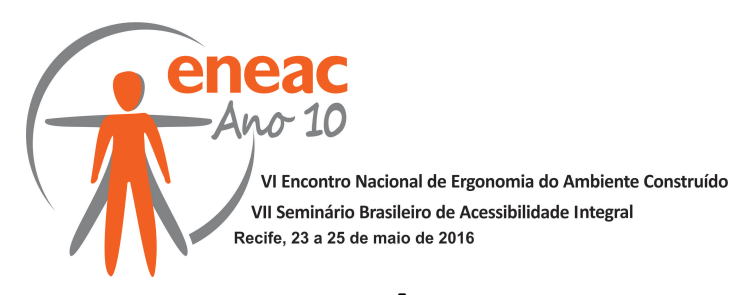

\title{
UMA PROPOSTA DE ABRIGO DE ÔNIBUS DE NATAL-RN A PARTIR DO MÉTODO DA GRADE DE ATRIBUTOS E DO DESIGN PARTICIPATIVO
}

\author{
OLIVEIRA, Lorena Gomes Torres de (1); \\ BESSA, Olavo Fontes Magalhães (2) \\ (1) Universidade Federal do Rio Grande do Norte, Mestranda \\ e-mail:lorenagomestorres@gmail.com \\ (2) Universidade Federal do Rio Grande do Norte, PhD. \\ e-mail:olavobessa@gmail.com
}

\begin{abstract}
RESUMO
Esta pesquisa tem por objetivo o desenvolvimento de uma proposta de abrigo de ônibus em NatalRN. Buscando conhecer informações sobre as necessidades das pessoas, por meio de instrumentos projetuais, utilizou-se o Método da Grade de Atributos - MEGA (BINS ELY, 1997) e o Design Participativo. O MEGA é capaz de avaliar as condições de espera das pessoas no abrigo de ônibus através da representação no objeto, simultaneamente, atributos e o comportamento dos usuários, através do Design Participativo, a partir da fala das pessoas, procura-se identificar seus desejos coletivos. Assim, foi possível elaborar diretrizes projetuais para o abrigo.
\end{abstract}

Palavras-chave: Abrigo de Ônibus; Método da Grade de Atributos; Design Participativo.

\begin{abstract}
This research aims to develop a bus shelter proposal in Natal, Brazil. Seeking to learn about the needs of people through projective instruments, we used Grid of Attributes Method - MEGA (BINS $E L Y, 1997)$ and the Participatory Design. The MEGA is able to evaluate the expected conditions of people in the bus shelter by representing the object both attributes and behavior of users, through the Participatory Design, from the speech of the people, we try to identify their collective desires. Thus, it was possible to develop projective guidelines for shelter.
\end{abstract}

Keywords: Bus stop shelters; Grid of Attributes Method; Participatory Design.

\section{INTRODUÇÃO}

Os abrigos de ônibus podem ser avaliados por várias técnicas de investigação projetuais. A presente pesquisa utilizou o Método da Grade de Atributos ou "MEGA" (BINS ELY, 1997) para avaliar as condições de espera das pessoas no abrigo de ônibus através da representação no objeto, simultaneamente, atributos e o comportamento das pessoas (aspectos bioclimáticos dos abrigos e relativos ao posicionamento/deslocamento das pessoas e às relações interpessoais). Propôs também a participação das pessoas através da declaração ou revelação de preferências (técnicas baseadas na opinião das pessoas). Além da conversa, levando em consideração as bases práticas do método de Paulo Freire, em um processo no qual o indivíduo é o sujeito e não um objeto; assim, as "palavras geradoras" da conversa sairiam do "universo vocabular" das pessoas ali questionadas, em uma situação existencial típica da vida dos indivíduos no ambiente problemático para promover o debate e incitar a fala deles. 


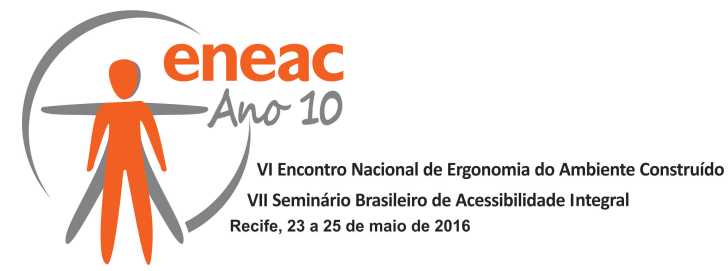

\section{CARACTERIZAÇÃO DO ESPAÇO}

O objeto de estudo foi o abrigo de ônibus da praça Luiz da Câmara Cascudo, localizada no bairro de Capim Macio, na cidade de Natal-RN, Brasil. Essa praça em que se localiza a parada destaca-se por sua importância social, dada sua localização central as margens da via expressa BR-101 e também por sua importância cultural, sendo uma das poucas praças na cidade que ocorrem vários eventos durante o ano.

É possível notar a proximidade a dois quebra-molas, um antes e outro depois do abrigo, ou seja, há uma redução de velocidade, o que traz uma maior segurança ao usuário e mais tempo para visualizar o ônibus que se aproxima. O abrigo estudado apresenta dois pilares em perfis metálicos e cobertura em fibra de vidro. Possuem bancos lineares também de metal. Não possui iluminação própria. É bastante desconfortável, principalmente pelo calor produzido por sua cobertura. A proteção contra o vento e a chuva é mínima. Em dias quentes, há desconforto térmico devido à excessiva absorção de calor do material.

\section{Figura 1 - Abrigo de Ônibus estudado}

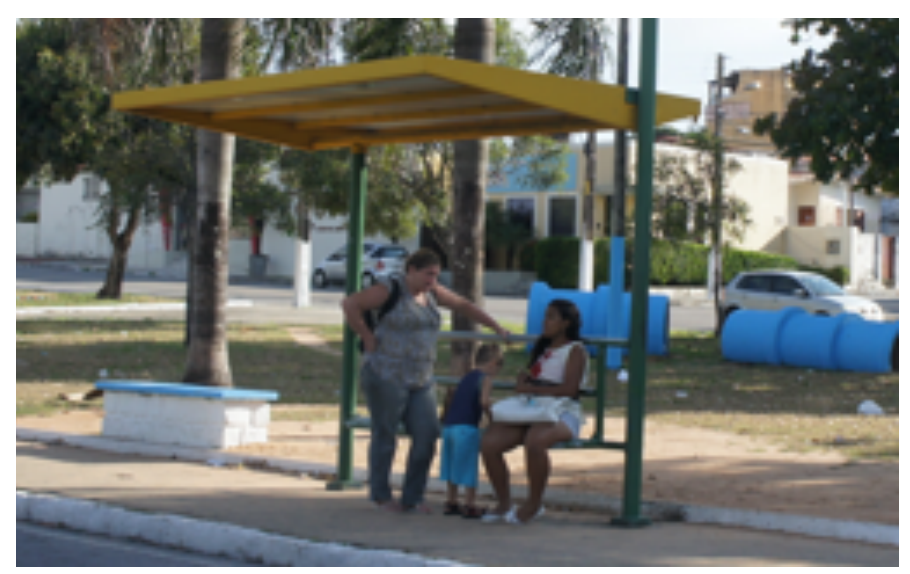

\section{APLICAÇÃO DO MÉTODO DA GRADE DE ATRIBUTOS - MEGA NA CONSTRUÇÃO DA AUTONOMIA DAS PESSOAS}

As medidas da célula segundo Panero \& Zelnik (1991) correspondem à largura máxima do corpo com vestimenta de inverno, percentil 95, apresentados na Figura 02 (BINS ELY, 1997). Esta célula corresponde ao "espaço pessoal", cuja forma não é um círculo, pois o homem tem necessidade de um espaço maior na dimensão anterior/posterior de seu corpo, a qual corresponde à profundidade do retângulo.

Nesta malha proposta foi desenhada a forma do objeto a ser avaliado, ou seja, a planta baixa do abrigo ônibus estudado, configurando as Grades de Atributos, conforme mostra a Figura 03. Essa malha é composta de células, que correspondem ao menor espaço ocupado por um ou mais indivíduos frequentadores do espaço avaliado.

É evidente que o usuário escolha um local no abrigo que the ofereça o nível de conforto mais próximo possível do desejado. Os atributos ergonômicos de projeto são definidos a partir das dimensões funcional, bioclimática e comportamental.

Quanto aos atributos da dimensão funcional, citamos: apoio (buscam apoiar-se em algum elemento quando chegam nos abrigos, como bancos, pilares); visibilidade/agilidade no embarque (alguns locais do abrigo permitem uma maior visibilidade do ônibus que se aproxima, observa-se também um deslocamento em direção ao meio-fio para visualizar o ônibus ou para agilizar o embarque). 


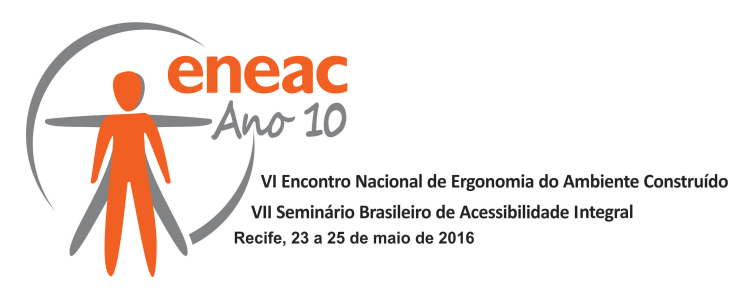

Figura 2 - Dimensões do corpo

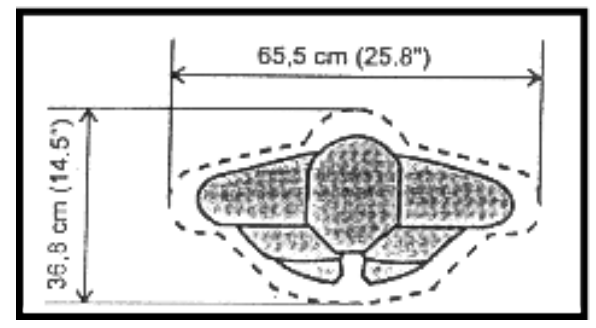

Figura 3 - Grade de Atributos aplicada no abrigo estudado

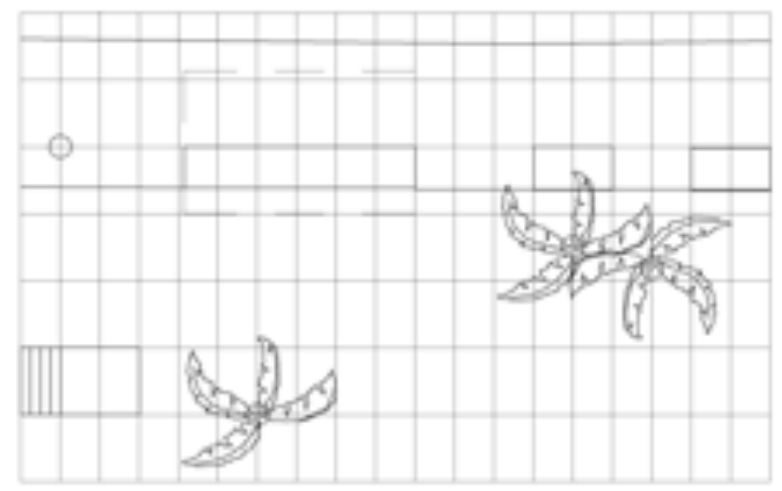

Características como sexo e faixa etária (Figura 4) são representadas. Na dimensão comportamental considerou-se fatores que podem influenciar no posicionamento do usuário se relacionam com a chegada do usuário no abrigo. Quanto a estes fatores consideramos: ordem de chegada (se o usuário chega em primeiro lugar no abrigo, pode escolher qualquer lugar para posicionar-se, ou seja, tem $100 \%$ dos locais disponíveis, à medida que já existam usuários posicionados, sua chance de escolha diminui - Figura 5); fluxo - direção e sentido (os usuários podem aproximar-se do abrigo vindo de diferentes direções, e a princípio, a escolha de um local para posicionar-se pode estar associada com uma maior proximidade desta direção - Figura 6); relações interpessoais (o local de posicionamento pode estar relacionado com o comportamento social do usuário, ou seja, o desejo de interagir com os demais - Figura 7).

Figura 4 - Representação das faixas etárias de usuários de sexo feminino e masculino.

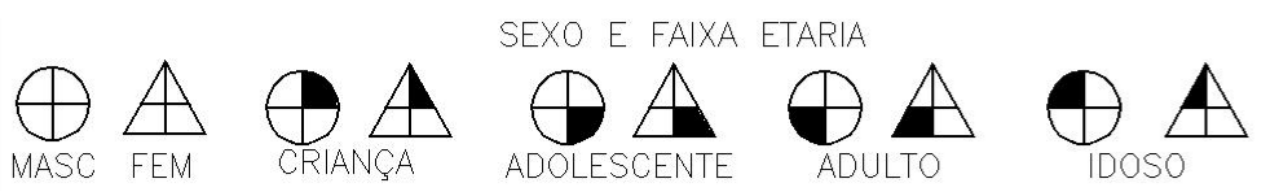

Figura 5 - Representação da ordem de chegada dos usuários no abrigo. 


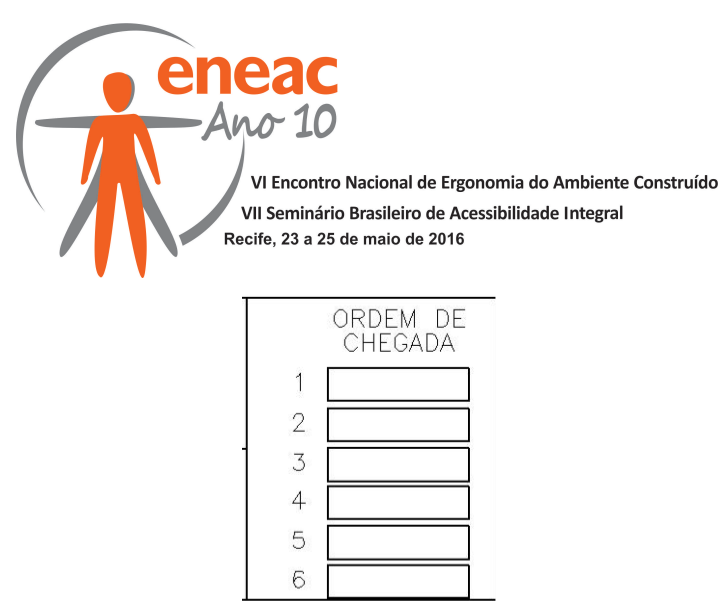

Figura 6 - Representação da direção e sentido da chegada dos usuários.

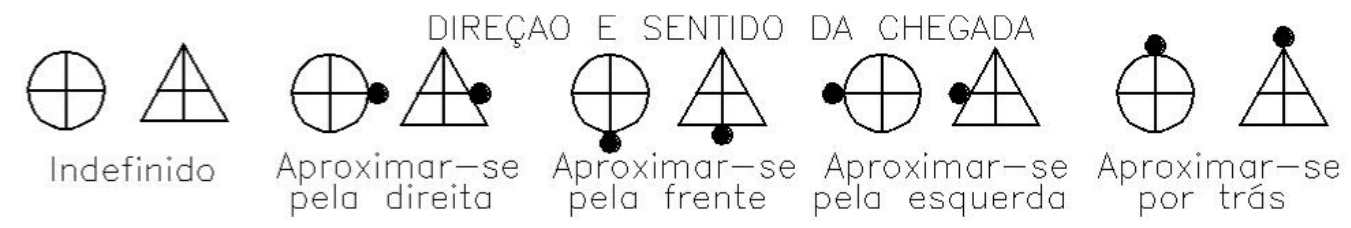

Figura 7 - Representação da existência de interação entre os usuários.

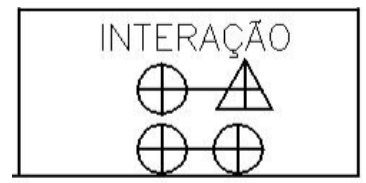

Figura 8 - Grade Comportamental preenchida.

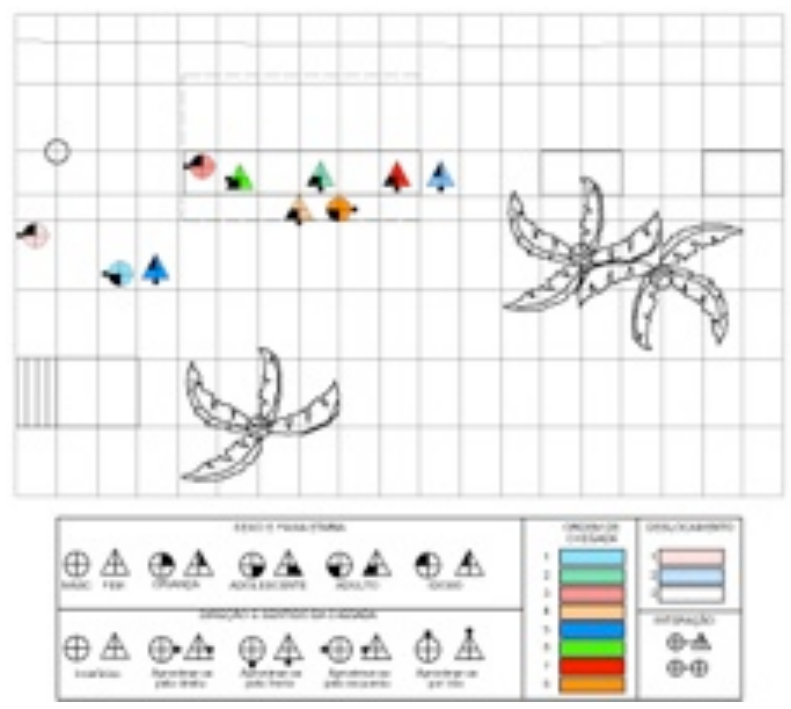

Os atributos relativos à dimensão bioclimática são: conforto térmico do apoio (todo elemento de apoio possui um determinado conforto térmico, que naturalmente varia nas diferentes horas do dia e nas diferentes estações do ano); sombra/sol (a opção de expor-se ao sol como proteger-se dele, em função de equilibrar sua sensação de conforto em relação ao meio ambiente). 


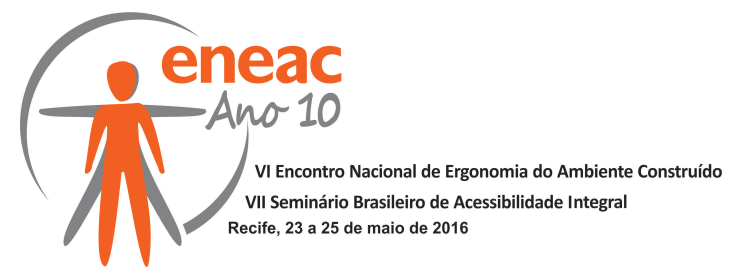

identificação do perfil do entrevistado, com as mesmas perguntas da outra Técnica e a ordenação de cartões imantados dispostos em uma pequena lousa, com diferentes alternativas de projetos de abrigos, efetuada pelo entrevistado. Com essa técnica foi possível quantificar e priorizar os desejos dos usuários através de suas opiniões "declaradas" em relação a uma combinação de atributos de projeto. A montagem dos cartões pressupôs a escolha de diferentes atributos de projeto e variações qualitativas de cada atributo - denominados de níveis (Figura 10), a saber:

- Acesso: protegido - deslocamento do usuário do abrigo ao ônibus com cobertura e plataforma elevada; desprotegido - sem cobertura e sem plataforma elevada.

- Proteção: com - possui cobertura e paredes laterais, protegendo-os das intempéries; sem - possui apenas cobertura.

- Mobiliário : com - possui banco, lixeira e iluminação; sem - não dispõe de mobiliário.

- Informação: com - possui quadro com horários e itinerário das diferentes linhas, além de informação sobre hora; sem - é desprovido de qualquer informação.

- Distância: atual - os abrigos permanecem implantados nos mesmos locais; atual +3 quadras - a distância atual percorrida pelo usuário até o abrigo é aumentada de 3 quadras; atual + 5 quadras - a distância atual percorrida pelo usuário até o abrigo é aumentada de 5 quadras.

Figura 10 - Opção com todos os benefícios e consequentemente uma maior distância a percorrer

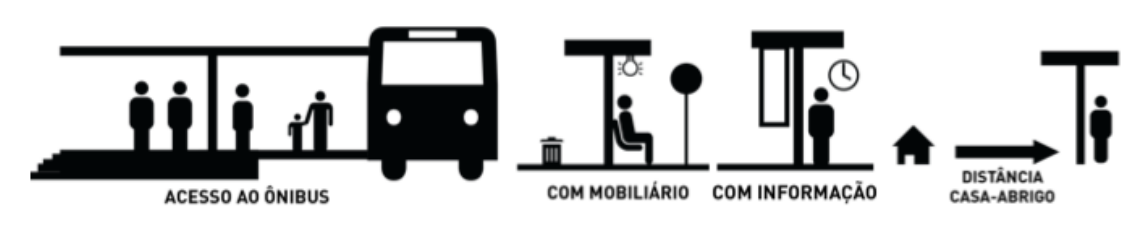

O atributo "distância" funciona como um fator de equilíbrio na relação custo/benefício, ou seja, quanto maior o número de atributos que melhoram a situação atual dos abrigos em um mesmo cartão, maior a distância a percorrer. Assim, a distância desempenha o papel de valor monetário: paga-se desta forma pela escolha de benfeitorias. Cada entrevistado deve ordenar por prioridade de escolha (decrescente) os atributos que julgar mais importantes para ele.

Além disso, perguntou-se também nos cartões imantizados a preferência do usuário no tipo de espera, ou seja, se ele prefere esperar o ônibus: em pé; sentado normalmente com os assentos que já existe em abrigos; sentado confortavelmente; sentado e com entretenimento. A outra questão levantada ao usuário foi que tipo de banco ele preferia. $E$ também, se caso o abrigo de ônibus fosse multifuncional qual a atividade que ele preferiria agregar: escutar música, balançar-se, usufruir de uma lanchonete, interagir ou ter acesso a livros para ler.

Com relação a conversa com as pessoas foi levado em consideração as bases práticas do método de Paulo Freire. Procurou-se iniciar a conversa com as pessoas que utilizam o abrigo de ônibus indagando "Qual o abrigo de ônibus dos seus sonhos?". Diante da pergunta, o indivíduo se deparava com um problema de sua vida cotidiana em um processo no qual ele era o sujeito e não um objeto; assim, as "palavras geradoras" da conversa sairiam do "universo vocabular" das pessoas ali questionadas. Com a linguagem simples e direta, acessível a qualquer pessoa independente de sua escolaridade, o questionamento é entendido. Cria-se um diálogo acerca do tema em questão e dá-se a liberdade da fala do indivíduo. O meio para a alfabetização é o diálogo, pregava Paulo Freire. Fazendo uma analogia entre a construção da autonomia das pessoas através da alfabetização e a 


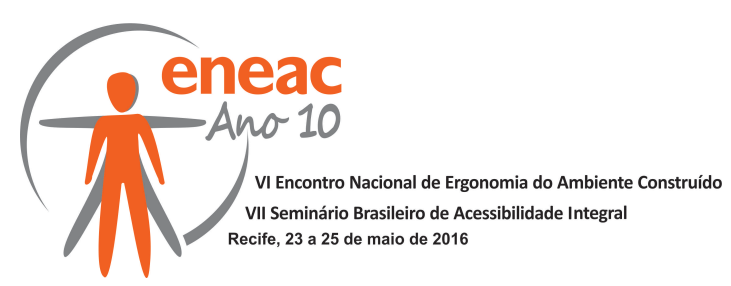

construção da autonomia através da participação do desenvolvimento de um projeto, podemos afirmar que o meio para um eficiente projeto participativo seria, além das técnicas de inquirição supracitadas, também o diálogo; foi preciso, portanto, criar em apenas uma pergunta (devido ao curto tempo de permanência da pessoa no abrigo) uma situação existencial típica da vida dos indivíduos no ambiente problemático para promover o debate e incitar a fala deles.

\section{RESULTADOS}

Foram observados 304 usuários posicionando-se no abrigo estudado (Grade de Posicionamento), sendo $53 \%$ do sexo feminino e $47 \%$ do sexo masculino. Deste total de usuários, 49 deslocaram-se enquanto aguardavam o ônibus, o que representa $16 \%$ do total da amostra. Esta segunda amostra - observada na Grade de Deslocamento - compõe-se de $59 \%$ mulheres e $41 \%$ homens, sendo semelhante ao perfil da primeira.

O objetivo deste trabalho estatístico é avaliar as prioridades dos usuários quanto aos atributos ergonômicos do objeto. Para avaliar as prioridades dos usuários relativas a este atributo é necessário conhecer a situação das células ocupadas quanto à sua exposição ao sol, à sombra total e à sombra parcial. Estas frequências estão organizadas na Tabela 1.

A leitura da Tabela 1, permite afirmar que os usuários posicionam-se com maior frequência em células que oferecem sombra total. Em seguida, quando estas estão ocupadas se posicionam em células que oferecem sobra parcial. Percebe-se que no abrigo, os usuários buscam proteger-se do sol com maior frequência no final da manhã, quando o sol está muito forte. Ficando apenas $7,85 \%$ dos usuários no sol, enquanto $92,15 \%$ estão na sombra total ou parcial. No final da tarde já é diferente: $27,79 \%$ dos usuários ficam exposto ao sol enquanto espera o ônibus, enquanto $72,21 \%$ procuram a sombra total ou parcial. Isto acontece devido ao sol está mais fraco nesse horário, os usuários se espalham mais na malha, não se importando de ficar exposto ao sol.

Tabela 1 - Percentagem das células do abrigo relativas ao fator "Sombra/sol"

\begin{tabular}{|l|c|c|c|c|}
\hline $\begin{array}{c}133 \text { células na } \\
\text { grade }\end{array}$ & $\begin{array}{c}\text { Manhã início } \\
\mathbf{2 8} \text { células } \\
\text { ocupadas }\end{array}$ & $\begin{array}{c}\text { Manhã final } \\
\mathbf{2 9} \text { células } \\
\text { ocupadas }\end{array}$ & $\begin{array}{c}\text { Tarde início } \\
\mathbf{6 4} \text { células } \\
\text { ocupadas }\end{array}$ & $\begin{array}{c}\text { Tarde final } \\
\mathbf{3 7} \text { células } \\
\text { ocupadas }\end{array}$ \\
\hline sol & $12,51 \%$ & $7,85 \%$ & $22,16 \%$ & $27,79 \%$ \\
\hline sombra & $61,36 \%$ & $50,98 \%$ & $43,11 \%$ & $38,88 \%$ \\
\hline parcial & $26,13 \%$ & $41,17 \%$ & $34,73 \%$ & $33,33 \%$ \\
\hline sombra+parcial & $87,49 \%$ & $92,15 \%$ & $77,84 \%$ & $72,21 \%$ \\
\hline
\end{tabular}

Para avaliar a importância do atributo apoio não basta calcular a percentagem de células que oferecem apoio. É necessário comparar esta percentagem com a frequência de células do abrigo em quatro horário diferentes do dia (início e fim da manhã e da tarde). Para isso, observou-se que das 133 células que constituem o abrigo, $69 \%$ das células estão sem apoio, $23 \%$ existe apoio e apenas $8 \%$ das células as pessoas podem sentar. Observou-se portanto que a maior parte das células não oferecem qualquer tipo de apoio aos usuários. $\mathrm{Na}$ Tabela 2, relacionou-se a frequência de utilização das células do abrigo nos quatro horários, discriminando o tipo de apoio. 


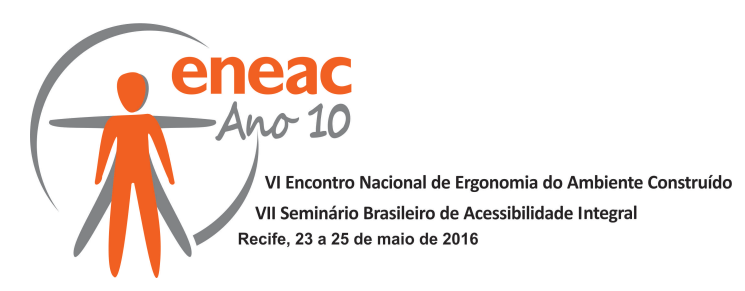

Tabela 2 - Frequência das células utilizadas em relação ao fator "Apoio” no abrigo, durante o dia.

\begin{tabular}{|l|c|c|c|c|}
\hline $\begin{array}{c}133 \text { células na } \\
\text { grade }\end{array}$ & $\begin{array}{c}\text { Manhã início } \\
\mathbf{2 8} \text { células } \\
\text { ocupadas }\end{array}$ & $\begin{array}{c}\text { Manhã final } \\
\mathbf{2 9} \text { células } \\
\text { ocupadas }\end{array}$ & $\begin{array}{c}\text { Tarde início } \\
\mathbf{6 4} \text { células } \\
\text { ocupadas }\end{array}$ & $\begin{array}{c}\text { Tarde final } \\
\mathbf{3 7} \text { células } \\
\text { ocupadas }\end{array}$ \\
\hline sem apoio & $27,28 \%$ & $35,31 \%$ & $35,34 \%$ & $42,60 \%$ \\
\hline com apoio & $17,04 \%$ & $17,64 \%$ & $36,52 \%$ & $27,77 \%$ \\
\hline sentado & $55,68 \%$ & $47,05 \%$ & $28,14 \%$ & $29,63 \%$ \\
\hline
\end{tabular}

Observou-se que no início da manhã, a frequência de utilização das células com apoio e sentado é de $17,04 \%$ e $55,68 \%$, respectivamente. É o horário que há uma maior busca de apoio. Além disso, no abrigo durante o final da manhã e início da tarde é semelhante ao números de usuários que buscam ficam sem apoio, cerca de $35 \%$ nos dois horários. No entanto, no fim da manhã $47,05 \%$ das pessoas sentam e $17,64 \%$ apenas se apoiam, enquanto que no início da tarde percebe-se que os usuários quase não utilizam os bancos, somente $28,14 \%$ das pessoas preferem sentar e o restante, cerca de $72 \%$, preferem ficar em pé com ou sem apoio. E no fim da tarde percebe-se que é o horário que as pessoas mais ficam em pé sem apoio, totalizando $42,60 \%$.

Das 133 células que compõem o abrigo, verificou-se que algumas não são utilizadas e outras são utilizadas com frequência variada. Procurou-se definir a frequência de utilização das células e avaliar que fatores intervêm nesta utilização. A Figura 11 mostram a frequência nas grades dos diferentes horários (manhã início, manhã final, tarde início e tarde final) no abrigo com a representação das células mais utilizadas observadas. Nos permitem concluir que é possível perceber que os horários do início da manhã e início da tarde são os únicos cujos usuários utilizam algumas células mais de 9 vezes, possui também uma distribuição um pouco mais homogênea no uso das diferentes células em que os 6 intervalos aparecem. E no final da manhã e final da tarde nenhuma célula é utilizada mais de 4 vezes. Percebe-se que as células mais utilizadas oferecem assento aos usuários e estão sob projeção da cobertura do abrigo ou da sombra da árvore, além disso, a localização das células são mais próximo do sentido de aproximação dos ônibus.

A grande maioria das pessoas entrevistadas são moradores que utilizam assiduamente o transporte público (53\%), ficando na frente dos estudantes da UFRN que por sua vez tem um percentual de $31 \%$. No entanto, não houve nenhuma entrevista com turista. A maioria das pessoas utilizam o ônibus tanto para trabalhar como para o lazer, sendo $57 \%$, e somente para trabalhar fica atrás com $36 \%$. A situação mais frequente é a do usuário que utiliza este meio de transporte por necessidade (86\%).

A maior parte dos usuários obtêm a informação sobre as linhas de ônibus através da informação de pessoas (37\%) ou de motoristas e cobradores de ônibus (20\%). Já devido ao hábito ou por dedução foram poucos $(9 \%)$, os demais (34\%) optaram por mais de uma fonte de informação.

A grande maioria dos entrevistados identifica o abrigo (98\%), enquanto uma menor parcela (2\%) não identifica. A identificação ocorre principalmente devido a concentração de pessoas (44\%), através de placas de se sinalização vem em segundo lugar (15\%) e o modelo padronizado por último (9\%). A grande maioria dos entrevistados $(68 \%)$ identifica o ônibus quando este se aproxima do abrigo, sendo que uma pequena parcela (32\%) não o identifica. 


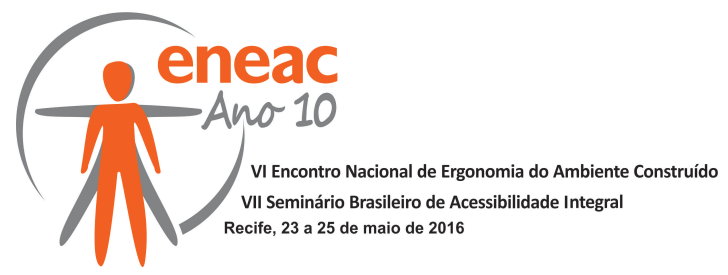

quando tem a proteção contra sol/chuva é ineficiente, os bancos são pequenos e não comportam todos que queiram sentar.

A distância é o atributo de maior importância na escolha dos cartões. Observa-se que apenas $15 \%$ da amostra aceita caminhar a maior distância (distância atual +5 quadras), sendo que a distância intermediária (atual +3 quadras) é aceita por $52 \%$ do total de entrevistados. Porém, neste método, a distância representou um parâmetro, uma "forma de pagamento" para compensar melhoras nos demais atributos. Não é um atributo de projeto, mas ressalta-se a importância da distância abrigo-casa para a satisfação do usuário quanto ao desempenho do sistema de transporte público.

$\mathrm{O}$ atributo informação vem em primeiro lugar, quase empatado com o atributo mobiliário urbano. O abrigo com informação é solicitado por $37 \%$ dos entrevistados, enquanto o atributo mobiliário é de $35 \%$ dos entrevistados. No atributo espera nenhum dos entrevistados prefere esperar o ônibus em pé, a maioria deles $(48 \%)$ prefeririam esperar com entretenimento, em segundo lugar (39\%) optariam esperar o ônibus confortavelmente, e poucos $(13 \%)$ prefeririam esperar sentado normalmente nos assentos que hoje já existem. Quanto a opção de ter mais de uma função além de esperar o ônibus, a maioria dos entrevistados se dividiram por optar por livros (27\%) e interação (27\%). Sobre a possibilidade de escolha do assento a maioria das pessoas, $82 \%$ escolheram o banco com divisão e encosto.

Diante da pergunta inicial "como seria o abrigo dos seus sonhos?" muitos falaram requisitos mínimos de um abrigo confortável, dentre eles: que seja bem iluminada, ventilada, com segurança, com lixeiras, bancos confortáveis, acessibilidade, cobertura eficiente que proteja de sol/chuva. Alguns optaram por algo que já tinham visto em outras cidades, como por exemplo: informações sobre linhas, itinerários e horários dos ônibus, disponibilidade de livros para ler, tomadas elétricas, encosto para apoiar seus pertences, transmissão de notícias, vendas de comidas através de máquinas, bebedouros, ar-condicionado, wi-fi, aplicativo com as rotas dos ônibus, sistema que avisasse que o ônibus estava vindo. Outros ainda, ousaram mais e a sua parada dos sonhos teria que ter: video game, consumir arte, bicicletas paradas e ao pedalar gera um resfriamento no ambiente do abrigo de ônibus, espelho d'água, ruído de fonte de água, muitos lugares para sentar.

Diante do questionamento, inicia-se um diálogo acerca do tema em questão e percebe-se a liberdade da fala do indivíduo sobre o ambiente problemático. A pessoa abordada é o sujeito e não um objeto, diante da autonomia exercida por ela. A partir da fala dessas pessoas e da análise do Método da Grade de Atributos coletados foi possível construir as hipóteses projetuais, e então, levantar os problemas encontrados no abrigo, a descrição contexto de cada problema e respectivas as soluções indicadas (Tabela 3 ).

Tabela 3 -Hipóteses projetuais

\begin{tabular}{|l|l|l|}
\hline \multicolumn{1}{|c|}{ Problema identificado } & \multicolumn{1}{|c|}{ Descrição contexto } & \multicolumn{1}{c|}{ Solução indicada } \\
\hline $\begin{array}{l}\text { O abrigo não contempla } \\
\text { diferença interpessoal } \\
\text { (dimensões antropométricas } \\
\text { dos usuários) e a possibilidade } \\
\text { de uso por deficientes físicos } \\
\text { permanentes ou temporários; } \\
\text { não está adaptado às } \\
\text { atividades do usuário (sentar- } \\
\text { se, acomodar pacotes). }\end{array}$ & $\begin{array}{l}\text { De qualquer forma o lugar é de } \\
\text { difícil acesso para cadeirantes. }\end{array}$ & $\begin{array}{l}\text { Abrigo maior para comportar } \\
\text { maior número de pessoas } \\
\text { com acessibilidade } \\
\text { com apoios para acomodar } \\
\text { pacotes e outros pertences }\end{array}$ \\
\hline
\end{tabular}




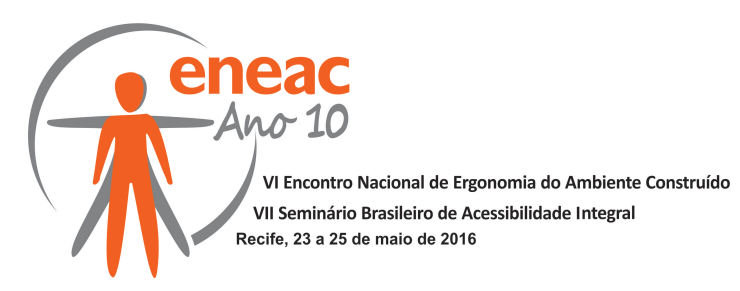

\begin{tabular}{|c|c|c|}
\hline Problema identificado & Descrição contexto & Solução indicada \\
\hline $\begin{array}{l}\text { São evidenciados problemas } \\
\text { relativos à segurança do } \\
\text { usuário durante a espera } \\
\text { (proximidade com o meio-fio) e } \\
\text { no acesso ao ônibus. }\end{array}$ & $\begin{array}{l}\text { O local estudado está entre } \\
\text { duas vias expressas (rodovia) } \\
\text { o que dificulta a estruturação } \\
\text { do espaço. }\end{array}$ & $\begin{array}{l}\text { Proteção no limite da parada } \\
\text { Plataformas niveladas ao } \\
\text { degrau do ônibus }\end{array}$ \\
\hline $\begin{array}{l}\text { Exposição do usuário à } \\
\text { radiação solar e chuva. Local } \\
\text { de muito calor em certos } \\
\text { horários do dia. }\end{array}$ & $\begin{array}{l}\text { A cidade de Natal-RN é } \\
\text { ensolarada o ano inteiro. }\end{array}$ & $\begin{array}{l}\text { Proteção eficiente contra } \\
\text { chuva e radiação solar, bem } \\
\text { como a escolha dos materiais. } \\
\text { Ventos dominantes } \\
\text { percorrerem o interior do } \\
\text { abrigo }\end{array}$ \\
\hline $\begin{array}{l}\text { Problemas relativos à } \\
\text { visibilidade (enxergar o ônibus } \\
\text { que se aproxima), legibilidade } \\
\text { (devido ao projeto), } \\
\text { leiturabilidade (não existe } \\
\text { sinalização), e não existe } \\
\text { informação sobre linhas, } \\
\text { percursos, etc. }\end{array}$ & $\begin{array}{l}\text { Toda a cidade sofre com a } \\
\text { deficiência de sinalização. }\end{array}$ & $\begin{array}{l}\text { Criar abrigos com estética } \\
\text { padronizada, ainda que cada } \\
\text { um tenha sua particularidade } \\
\text { de público, necessidades, } \\
\text { entorno. } \\
\text { Deve existir sinalização } \\
\text { adequada, informações sobre } \\
\text { linhas, percursos, horários dos } \\
\text { ônibus. }\end{array}$ \\
\hline $\begin{array}{l}\text { Problemas quanto à } \\
\text { manutenção, conservação, } \\
\text { limpeza, vandalismo, } \\
\text { depredação. }\end{array}$ & $\begin{array}{l}\text { Os materiais, os objetos de } \\
\text { uso público predispõem a ação } \\
\text { de vandalismo. }\end{array}$ & $\begin{array}{l}\text { Escolha de materiais que } \\
\text { favoreçam a conservação }\end{array}$ \\
\hline $\begin{array}{l}\text { Não transmite sensação de } \\
\text { segurança ao usuário, devido à } \\
\text { ausência de iluminação } \\
\text { artificial à noite e devido à falta } \\
\text { de informação (horários dos } \\
\text { ônibus, percursos). }\end{array}$ & $\begin{array}{l}\text { A noite o espaço se desertifica } \\
\text { e a iluminação fraca não } \\
\text { contribui para melhorar a } \\
\text { segurança do local. }\end{array}$ & $\begin{array}{l}\text { Abrigo deve ter iluminação } \\
\text { eficiente durante a noite. } \\
\text { Deve existir informações sobre } \\
\text { linhas, percursos, horários dos } \\
\text { ônibus. }\end{array}$ \\
\hline
\end{tabular}

\section{CONSIDERAÇÕES FINAIS}

A presente pesquisa fez uso do Método da Grade de Atributos ou "MEGA" (BINS ELY, 1997) capaz de medir influências recíprocas entre diferentes fatores que influenciam o posicionamento das pessoas em abrigos de ônibus, além da participação das pessoas, levando em consideração as bases práticas do método de Paulo Freire. Unindo observação e a opinião das pessoas foi possível identificar os problemas e desenvolver hipóteses projetuais para uma futura proposta de abrigo de ônibus em Natal-RN, como desmembramento do trabalho. Procurando solucionar os problemas do cotidiano das pessoas através de soluções vindas delas mesmas que usufrui do ambiente problemático. É de caráter ímpar para a solução projetual tal método, onde não provem apenas de técnicas, e sim de uma troca de saberes, num processo inter e transdisciplinar.

Este trabalho considera a possibilidade de expansão dessa prática participativa em projetos de Design para outros ambientes, como uma praça pública por exemplo, fomentando assim, a participação das pessoas e o Método da Grade de Atributos. Com a intenção de criação de espaços de uso público, onde o próprios usuários expressem suas próprias necessidades e desejos traduzidas em projeto. 


\section{REFERÊNCIAS BIBLIOGRÁFICAS}

BESSA, Olavo Fontes Magalhães. A agradabilidade do espaço urbano construído da cidade de Alfenas(MG): Uma abordagem ergonômica. Dissertação. Programa de Mestrado em Design. PUCRJ, 2001.

BINS ELY, Vera Helena Moro. Avaliação de fatores determinantes no posicionamento de usuários em abrigos de ônibus a partir do método da grade de atributos. Tese (Engenharia de Produção) da UFSC, 1997.

FREIRE, Paulo. Pedagogia da autonomia: saberes necessários à prática educativa. $25^{\mathrm{a}}$ ed. São Paulo: Paz e Terra, 2011.

GEHL, Jan. Cidade para pessoas. São Paulo: Perspectiva, 2013.

JACOBS, Jane. Morte e vida de grandes cidades. São Paulo: Martins Fontes, 2001.

LEFEBVRE, Henri. Direito à Cidade. São Paulo: Editora Centauro, 2010.

LYNCH, Kelvin. A imagem da cidade. São Paulo: Maris Fontes, 1997.

MACEDO, Carla Ferreira. Avaliação dos Atributos Determinante na Escolha de Ambientes de Permanência em Espaço Livre Público a partir do Método da Grade de Atributos. Dissertação (Mestrado em Engenharia de Produção) da UFSC, Florianópolis, 2003.

PANERO, Julius \& ZELNIK, Martin. Las Dimensiones Humanas en los Espacios Interiores: estándares antropométricos. México: ed. Gustavo Gili, 1991.

ROSA, Marcos L. Handmade Urbanism: From Community initiatives to Participatory Models. Berlim: Jovis, 2013.

SPINUZZI, C The methodology of participatory design. Technical Communication, Vol. 52, n. 2, pg. 163-174, 2005. 